\title{
SMALL BOWEL OBSTRUTION DUE TO MECKEL'S DIVERTICULUM: A CASE REPORT
}

\author{
Malaya Krishna Nayak¹, Ashok Kumar Nayak², Rabinarayan Guru³, Sandeep Mishra4
}

\section{HOW TO CITE THIS ARTICLE:}

Malaya Krishna Nayak, Ashok Kumar Nayak, Rabinarayan Guru, Sandeep Mishra. "Small Bowel Obstrution due to Meckel's Diverticulum, a Case Report". Journal of Evolution of Medical and Dental Sciences 2014; Vol. 3, Issue 19, May 12; Page: 5179-5181, DOI: $10.14260 /$ jemds/2014/2570

ABSTRACT: Meckel's Diverticulum is the most common congenital anomaly of the intestine. Its common complications include hemorrhage, inflammation, and intestinal obstruction. Small bowel obstruction due to Meckel's Diverticulum is a rare complication. Herein, we present a case of small bowel obstruction due to the mesodiverticular band of Meckel's Diverticulum.

KEYWORDS: Meckel's Diverticulum, Intestinal obstruction.

INTRODUCTION: Meckel's Diverticulum is the most common congenital anomaly of the gastrointestinal system.1,2 It is caused by the failure of vitelline duct to obliterate.,3,4 Most of them are detected incidentally during a surgical procedure or autopsy. Hemorrhage, intestinal obstruction and diverticulitis are the most common presenting features.3,4 This case report present small bowel obstruction due to mesodiverticular band of Meckel's Diverticulum.

CASE REPORT: An 18 yr. old male presented to emergency OPD with complaints of an abdominal pain, vomiting \& absolute constipation for 2 days. He was treated conservatively \& referred from a local hospital. On admission, he was found having poor body built, dehydrated, ill looking. On examination, his abdomen was distended with diffuse tenderness \& no palpable lump. Bowel sound was absent.

Digital rectal examination (DRE) revealed empty rectum. Plain X-ray abdomen in erect position showed gaseous distention with multiple air fluid level (fig.1). USG of abdomen showed dilated bowel loops with fluid. On investigation of blood, TLC was raised with Neutrophilia, and all other tests including serum electrolyte \& renal function test were within normal limit. It was diagnosed to be a case of small gut obstruction and planed for exploratory laparotomy.

On exploratory laparotomy gross dilatation of the small gut and collapsed large gut were found. Dilation was up to the terminal ileum, about 2 feet away from the ileo-coecal valve, markedly compressed by a mesoventricular band leading to gangrene of that part (fig. 2). Obstruction was due to the trapping of small bowel by a mesodiverticular band (fig. 3). After separating the band ileal loops made free. Resection and end to end ileo-ileal anastomosis was done. Post-operative period was uneventful and the patient was discharged after the $7^{\text {th }}$ day of hospitalization.

DISCUSSION: Meckel's Diverticulum is the most common congenital anomaly of the gastrointestinal tract. Meckel's Diverticulum was first reported by Fabricius Hildanus in 1598 and then described in detail by Johann Friedrich Meckel, in 1809.2,3 It is the remnant of the persistent intestinal part of the vitello-intestinal or omphalo-enteric duct. It is true diverticulum found in the anti-mesenteric boarder comprising of all intestinal layers. It is found in $2 \%$ of total population, 2 feet from the ileo-caecal junction, and 2 inch in length and has 2 types of common ectopic tissue (gastric and pancreatic).2,3,4 


\section{CASE REPORT}

The frequent complications of Meckel's Diverticulum are hemorrhage, intestinal obstruction and diverticulitis. Intestinal obstruction is the second common completion, which is due to trapping of bowel loops by mesodiverticular band, volvulus of the diverticulum, intussusception and Litre's Hernia.5, 6 In our case it was due to a mesoventricular band which could not be diagnosed by the conventional radiography or sonography.

Surgery is the main stay of treatment. The diverticulum is excised in a "V" form and smallintestine is sutured transversely. If the base of the diverticulum is wide or the intestine appears nonviable, resection and end to end ileo-ileal anastomosis may be required.6,7

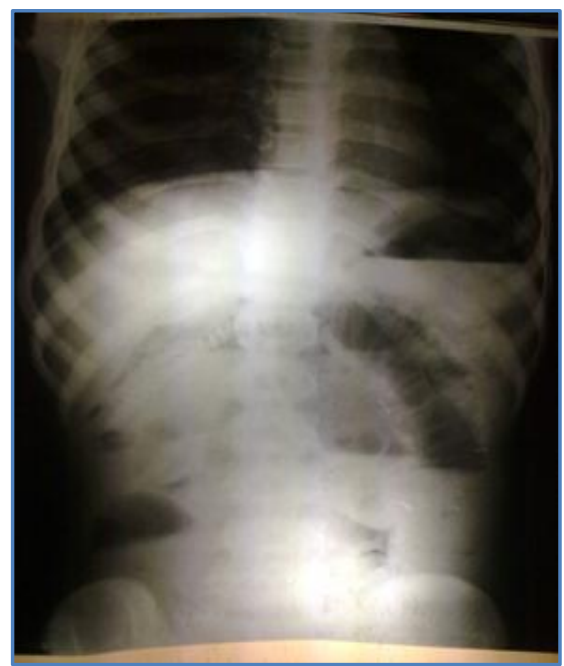

Figure 1: X-Ray showing multiple air - fluid levels

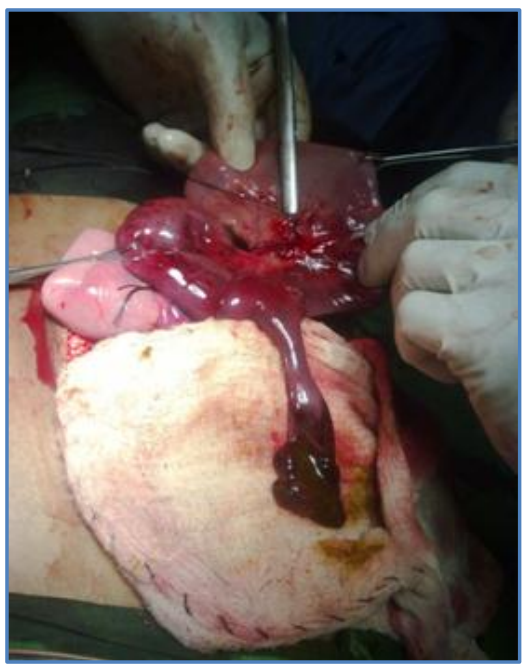

Figure 2: Exploratory Laparotomy

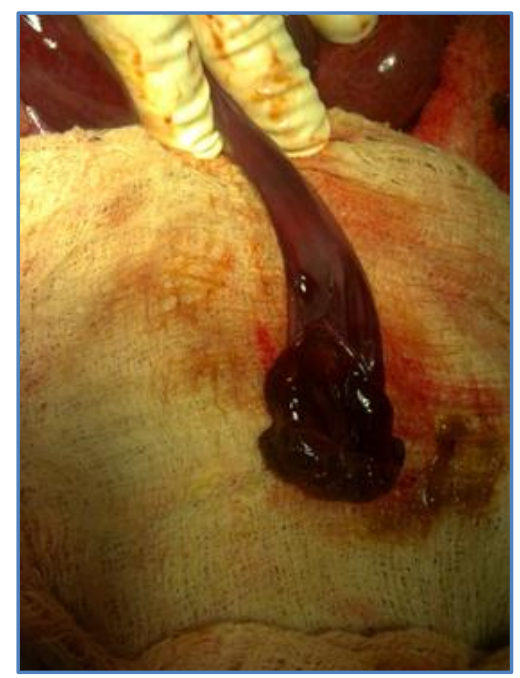

Figure 3: Meso diverticular band 


\section{REFERENCES:}

1. Gordon Carlson \& Jonathan Epstion; Intestinal Diverticula; The small and large intestines; Bailey \& Loves Short Practice Of Surgery; 26 ${ }^{\text {th }}$ ed; 2013; CRC Press; 69; 1169-1170.

2. Ali Tavakkolizadeh, Edward E. Whang, Stanley W. Ashley, Michael J. Zinner. Meckel's Diverticulum; Small Intestine; Schwartz's Principles Of Surgery; 9th ed; 2010; Mc Graw Hill; 28; 1002-1004.

3. Jessica K. Smith, Jennifer C. Carr, Joseph J. Cullen. Meckel's Diverticulum; Small Bowel Diverticula. Shackelford's Surgery of the Alimentary Tract; Vol-I, 7th ed; 2012; Elsevier Saunders; 55; 695-698.

4. Shaun McKenzie, B. Mark Evers. Meckel's Diverticulum; Small intestine. Sabiston Textbook of Surgery; Vol-II; 19th Ed; Elsevier; 50; 1268-1270.

5. William H. Peranteau, Douglas S. Smink. Meckel's Diverticula; Apendix, Meckel's And Other Small Bowel Diverticula. Maingot's Abdominal Operations; $12^{\text {th }}$ ed; Mc Graw Hill; 31; 643-644.

6. Prall RT, Bannon MP, Bharucha AE. Meckel's diverticulum causing intestinal obstruction. Am J Gastroenterol 2001 Dec; 96 (12): 3426-3427.

7. Khalifa Ali Al Jabri, Ahmed El Sherbini. Small Bowel Obstruction due to Meckel's Diverticulum: A Case Report. OMJ 2012.18.

\section{AUTHORS:}

1. Malaya Krishna Nayak

2. Ashok Kumar Nayak

3. Rabinarayan Guru

4. Sandeep Mishra

\section{PARTICULARS OF CONTRIBUTORS:}

1. Assistant Professor, Department of Surgery, V.S.S. Medical College, Burla, Odisha.

2. Assistant Professor, Department of Surgery, V.S.S. Medical College, Burla, Odisha.

3. Post Graduate Student, Department of Surgery, V.S.S. Medical College, Burla, Odisha.

4. Post Graduate Student, Department of Surgery, V.S.S. Medical College, Burla, Odisha.

\section{NAME ADDRESS EMAIL ID OF THE CORRESPONDING AUTHOR:}

Dr. Malaya Krishna Nayak, Assistant Professor, Department of Surgery, V.S.S. Medical College, Burla-768017, Odisha. E-mail: drmalayanayak@gmail.com

Date of Submission: 08/04/2014. Date of Peer Review: 09/04/2014. Date of Acceptance: 18/04/2014. Date of Publishing: 09/05/2014. 